\title{
LANDSLIDE EXTRACTION FROM SENTINEL-2 IMAGE IN SIWALIK OF SURKHET DISTRICT, NEPAL
}

\author{
P. B. Budha ${ }^{1,2, *}$, A. Bhardwaj ${ }^{3}$ \\ ${ }^{1}$ Centre for Space Science and Technology Education in Asia and the Pacific, Dehradun, India \\ ${ }^{2}$ Greenhood Nepal, Kathmandu, Nepal - padambudha88@gmail.com \\ ${ }^{3}$ Photogrammetry and Remote Sensing Department, Indian Institute of Remote Sensing, Dehradun, India - ashutosh@iirs.gov.in
}

Commission V, WG V/7 \& Commission IV, WG IV/6

KEY WORDS: Landslide Inventory, Object-Based Image Analysis, Image Segmentation, Semiautomatic Feature Extraction

\begin{abstract}
:
Locating landslides and determining its extent is deemed an important task in estimating loss and damage and carry out mitigation works. As landslides are recurring phenomena in the research site, Siwalik Hills of western Nepal, freely available Sentinel-2 satellite images were considered to delineate landslides. The method employed in this process was Object-Based Image Analysis carried out in eCognition software using multiresolution segmentation algorithm. Parameters taken for segmentation were a scale of 20, the shape of 0.3 , and compactness of 0.5 . When a threshold value of $<0.35$ in NDVI was used to distinguish landslides from image objects, some non-landslide objects were also selected. These false positives were removed successively using the threshold values on different bands, band ratios, slope information, hillshade and geometrical properties of image objects. There were altogether 264 landslides detected in the study area with size ranging from $300 \mathrm{~m}^{2}$ to $1675 \mathrm{~m}^{2}$ and landslide density of approximately 2 per $\mathrm{km}^{2}$. The accuracy, when compared to reference inventory, showed correctness and completeness measuring $80.28 \%$ and $66.27 \%$ respectively. These results showed semi-automatic landslide extraction was successful and Sentinel-2 can be used for similar tasks in other areas of Siwalik.
\end{abstract}

\section{INTRODUCTION}

Landslides are annual problem in the Siwalik Hills, which can be related to the continuous tectonic movement. Especially in monsoon season, when rainfall acts as triggering agent, numerous landslide incidents can happen. Steep terrain, rugged topography and anti-dip slopes are indications in hills of the Siwalik where landslide can occur frequently (Ghimire, 2010). Few landslides which cause harm or loss to human systems are reported. Here many landslides remain unnoticed as they primarily occur in forested areas or areas far from settlements. Inventory and mapping of landslides is an important task that can incorporate all landslide incidents and help to assess the land cover change of the entire Siwalik.

Siwalik, also called Shivalik in India and Churia in Nepal, is a range of hills that rise abruptly from southern plain lands (Terai) with east-west arch (Dhital, 2015). This made Siwalik the first topographic rise as well as southernmost range in the Himalayas. This is shown in Figure 1 as a thin strip spanning east-west along southern Nepal. Their peaks rise from $300 \mathrm{~m}$ and reach up to 2000 $\mathrm{m}$ whereas the width of this range is from $10-15 \mathrm{~km}$ in Nepal which can be found up to $50 \mathrm{~km}$ elsewhere. The Siwalik Hills is divided into three divisions based on the major rock types found in them. These divisions are lower, middle, and upper Siwaliks distinguished by mudstones, sandstones and conglomerates respectively (Schelling et al., 1991). These sedimentary rocks are young, very fragile and highly weathered. They are easily washed away by rainfall as most materials are in the weathered state. Thus, the landforms of the Siwalik are controlled by the tectonic processes, and by weathering and mass wasting.

The trends of landslide research in Nepal showed that most of the studies are focused on hazard zonation (Alexander, 2004; Dahal et al., 2010; Bhatt et al., 2013) or susceptibility mapping (Ghimire, 2010; Kayastha et al., 2013: Budha et al., 2016). Even though landslide inventory is starting step in all these studies, very less literature can be found devoted to the proper inventory of landslides. In Nepal, most of the inventories are done from field visits as manual sketching on topographic maps which are digitized later. Very less had made the use of satellite imageries. The process of field inventory of landslides is time- consuming and need more human and economic resources. There is a requirement of a process for landslide inventory which can be done from satellite imageries and the process should be efficient in terms of resource consumption and output of the products.

As of now, there are free imageries from Landsat- 8 and Sentinel2 satellites, provided by NASA (National Aeronautics and Space Administration) and ESA (European Space Agency) respectively, which can be used for the purpose of feature extraction. The features can be landslides among others. Also, there is a need for the development of a proper set of rules or algorithms that can be used for landslide mapping. Therefore this research is intended to use free imageries for the purpose of landslide inventory. The major objective of this study is to semiautomatically extract landslide features from Sentinel-2 image in Siwalik Hills of Nepal.

\section{MATERIALS AND METHOD}

\subsection{Study Area}

The research was carried out in two micro-watersheds located in the Siwalik region of western Nepal. As shown in Figure 1, those two micro-watersheds are Bheriganga and Lekhgaun lying in Surkhet District of Karnali Province. Total area Bheriganga

\footnotetext{
* Corresponding author
} 
along with Lekhgaun measured $146.452 \mathrm{~km}^{2}$ and the centroid of location is $81.6832^{\circ} \mathrm{E}$ and $28.44808^{\circ} \mathrm{N}$. Elevation in this range is from $355 \mathrm{~m}$ to $1380 \mathrm{~m}$.

The vegetation of these hills comes under upper tropical, and subtropical with Shroea robusta, Dlabegria sissoo, Acacia catechu, Schima wallichii, Castanopsis indica, and Chir Pine as dominant vegetation and Alnus nepalensis along wet areas of streams and gullies. The rainfall in these Siwalik is in the range of 2000-2500 $\mathrm{mm}$ per year. Rainwater significantly affects the soft and loose Siwalik strata leading to flash floods and debris flows (Dhital, 2015). Siwalik falls under sub-tropical to temperate climate, with temperature ranges from $20-24^{\circ} \mathrm{C}$ (Karki et al., 2016), having dry winter and hot summer.

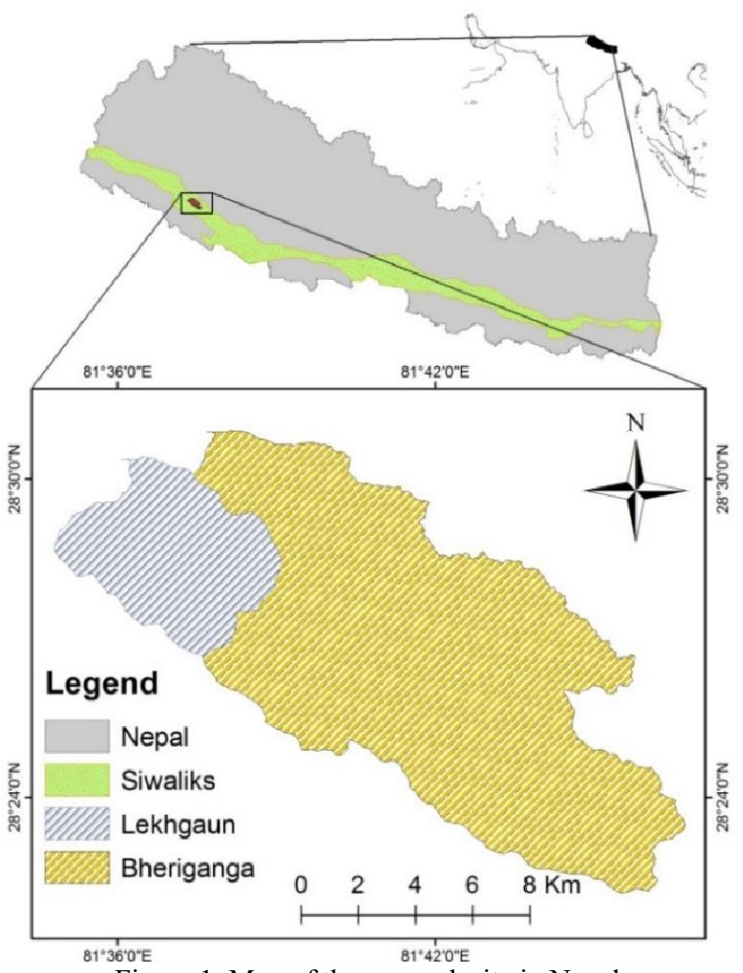

Figure 1. Map of the research site in Nepal

\subsection{Datasets}

The data used in this study is level $1 \mathrm{C}$ image product from Sentinel-2A satellite. Images of level 1C product are orthorectified and have ToA (Top of Atmosphere) reflectance as its DN (digital number) values. The tile number of the image used for Bheriganga catchment was T444RNS and imagery date is of 9 February 2016. Among the 13 spectral bands captured by Multispectral imager (MSI), four bands of $10 \mathrm{~m}$ spatial resolution visible and near-infrared (VNIR) bands were used in this experiment

$12.5 \mathrm{~m}$ high-resolution Digital Elevation Model (DEM) was obtained from Alaska Satellite Facility (ASF). ASF had corrected geometry and radiometry of Synthetic Aperture Radar (SAR) data and produced this radiometrically terrain corrected (RTC) DEM as one product. ASF-RTC-DEM image in GeoTIFF format used in this research was ALPSRP091700550 acquired on 14 October 2007

\subsection{Method}

Figure 2 represents the flow chart of processes conducted in this study. Here different processes are grouped into three parts: first multiresolution image segmentation is shown by a dotted line, second potential landslide candidate selection and removal of false positives depicted by a dashed line, and finally accuracy assessment enclosed by a dot-dashed line.

The method used in this study is Object-Based Image Analysis (OBIA) (Hay, Castilla, 2006) which was developed in order to do the automatic extraction of image features. OBIA had been used to extract regular features like buildings (Karna, Bhardwaj, 2014), irregular features like tree canopy (Gustafson et al., 2018) or landslides (Chen et al., 2018), and also in landuse land cover classification (Cai et al., 2019).

OBIA involves two steps: image segmentation and object classification. In image segmentation pixels having near or same brightness values are grouped into s single structure which can be delineated as an individual region (Aksoy, Akcay, 2005) and treated as a single object. Then objects of the segmented image were are classified using certain classification algorithm (Cheng, Han, 2016). Classification and segmentation in OBIA is still an iterative process and much iteration is required to achieve final boundaries for a specific feature of interest

The multi-resolution segmentation algorithm was used for image segmentation. The algorithm is based upon a bottom-up region-merging process which starts with one pixel to form an image object (also called region). At each step, a pair of image objects get merged into larger objects. Here the merging decision is based on local homogeneity criteria, that describe the similarity of adjacent image objects (Baatz, Schäpe, 2000). In the homogeneity criteria, three parameters are taken i.e. scale, colour and shape.

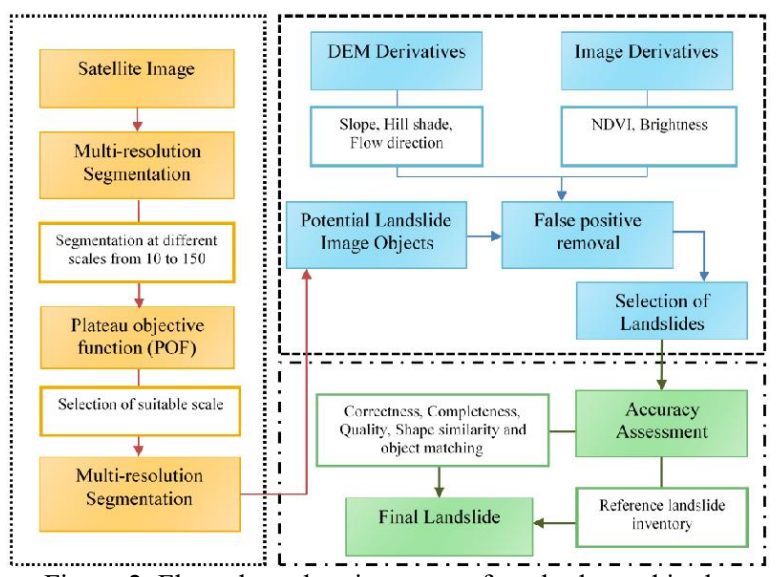

Figure 2. Flow chart showing steps of methods used in the research

The scale parameter is applied to determine the maximum acceptable heterogeneity for the resulting image objects. When input sale value is small the segmentation results into a higher number of image objects that are small in size and vice-versa. It can be said that the scale parameter is directly proportional to the size of image objects but inversely proportional to the number of image objects.

The shape and compactness parameter values range from 0 to 1 . The value of the shape factor modifies the colour criteria as the colour a criterion is defined as 1-shape. Therefore, a low shape 
value will put more emphasis on colour which is most useful for creating meaningful objects when multispectral images are used. This shape parameter is further dependent upon compactness and smoothness and these two are related to each other as compactness equals to 1 -smoothness.

Plateau Objective Function (POF) (Espindola et al., 2006) was used to find the optimal scale which is the combination of intrasegment variance $(v)$ and Moran's I index $(I)$. This objective function is also called the Global Score (GS) (Böck et al., 2017).

$v=\frac{\sum_{i=1}^{n} a_{i} * v_{i}}{\sum_{i=1}^{n} a_{i}}$

where, $a_{i}$ the area, and

$\mathrm{V}_{\mathrm{i}}$ is the variance of segment $\mathrm{i}$.

$I=\frac{n}{S_{o}} * \frac{\sum_{i=1}^{n} \sum_{j=1}^{n} w_{i, j} z_{i} z_{j}}{\sum_{i=1}^{n} z_{i}^{2}}$

where, $z_{i}$ is a deviation of the brightness value of objects $i$ from its mean $\left(x_{i-}-\bar{x}\right)$

$w_{i, j}$ denotes spatial weights between objects $i$ and $j$ which is 1 for adjacent region or 0 otherwise,

$n$ is the total number of objects, and

$S_{o}$ refers to the aggregate of all spatial weights

$S_{o}=\sum_{i=1}^{n} \sum_{j=1}^{n} w_{i, j}$

Variance is the measure of the intrasegment heterogeneity whereas Moran's I index is a measure of spatial autocorrelation. The objective function is defined as:

$F(v, I)=F(v)+F(I)$

where, functions $F(v)$ and $F(I)$ are normalized functions of $\mathrm{v}$ and I, respectively, derived from the minimum-maximum normalization method.

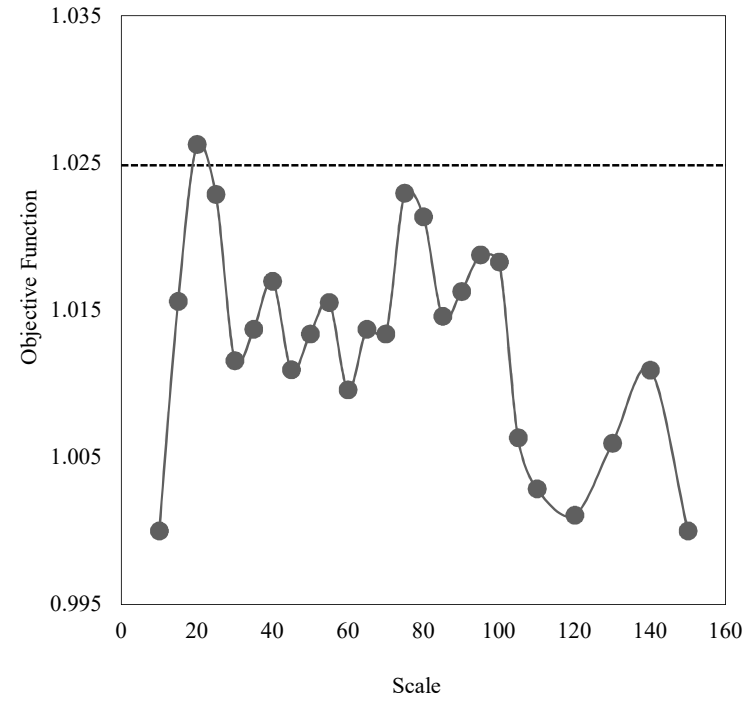

Figure 3. Plot of objective function versus scale with a dotted line showing a plateau
Plateau function ( Martha et al., 2011) was used to demarcate the lower boundary of the plateau which is given as

$F($ plateau $)=F(v, I)_{\max }-\sigma$

where, $F(v, I)_{\max }$ is maximum value and $\sigma$ denotes the standard deviation of the objective function calculated for different scales.

Before selection of optimal scale, multiresolution image segmentation was done at 25 different scales i.e., 10, 15, 20, 25, $30,35,40,45,50,55,60,65,70,75,80,85,90,95,100,105$, $110,120,130,140$, and 150 taking $10 \mathrm{~m}$ VNIR bands of Sentinel2 . The objective function values ranged from 1 to 1.0263 whereas plateau function value was found to be 1.02. In Figure 3, it can be observed that at a scale of 20 the objective function surpass the plateau function. Hence, the scale of 20 was considered favourable for further process.

Derivatives of DEM as wells indices developed from images now had a crucial role in the separation of potential landslides and removal of false positives. Here, Image derivatives used were NDVI (Normalized Differential Vegetation Index) and mean brightness. NDVI is estimated from the near-infrared and red bands of Sentinel-2 images and its values range from -1 to +1 . NDVI is used to separate vegetated areas from those nonvegetated areas by using certain threshold values. Mean brightness is the average of brightness values of four VNIR bands of $10 \mathrm{~m}$ resolution. DEM derivatives used were slope, flow direction and hillshade. A slope can be used to differentiate gentle slope surface where landslides occurrence is rare from steep slope surfaces. Hillshade can be used to remove the potential landslides of shadow areas which are false positives.

The scale of 20 was used for the final segmentation process to demarcate landslide. At this time brightness, slope, hillshade and flow direction were also taken as input image along with VNIR bands of Sentinel-2 image. After the segmentation process, NDVI was calculated as a customized feature for image objects in eCognition software. NDVI threshold of 0.3 was used to differentiate image objects into objects that may be a part of or consists of potential landslides and objects which are nonlandslides. Among the potential landslides, other features like sand, barren lands, crop fields, urban area, and roads were also present. Such objects in potential landslides were taken as false positives and removed subsequently.

Removal of false positives and selection of landslides is an important step after potential landslides are distinguished from all image objects. The different criteria were developed as ruleset during this process. Here, different spectral characteristics, image derivatives, DEM derivatives, the geometry of image objects and relations of image objects were criteria used to remove false positives. In Figure 4 we can see different stages from image segmentation to selection of landslide candidates.

Water bodies in this area were removed using the values of NDVI, mean NIR and mean slope as $<0.125,<1500$ and $<15^{\circ}$ respectively. A sand area in river body was separated using the border to river and distance to river criteria at first hand along with NDVI and slope, then finally mean green $>1100$, NDVI $<$ 0.2 and mean slope $<20^{\circ}$ was used to define the remaining sand area in image objects of potential landslides. Similarly, the shadow area was distinguished by using brightness $<10$, hillshade $<75$ and flow direction 30-70 along with NDVI value $>0.1$ Removal of linear features and smaller random segments geometry characteristics of image objects were used. 
Length/width (1/b) ratio and asymmetry of image objects $>3$ and $>0.9$ respectively were found better for distinguishing linear features. Other linear features that were not detected were added by continuity relations as a border to former linear features of equal to 1 pixel. Length $<5$, width $<3$ and $1 / b<2$ was used to remove random pixel that appeared as shot noise. Agriculture area was separated using NDVI $>0.1$, mean slopes $<20^{\circ}$ and mean blue $>1155$ values. Remaining crop fields were added by using distance relations as objects at $<15$ pixels distance to the former classified agricultural area. Sparse vegetation that was separated as potential landslides were removed using NDVI $>0.25$ man slope $>28.5$ and mean green $<1500$. Rocky areas and escarpment were separated using slope criteria of slope $30^{\circ}-45^{\circ}$ and $>45^{\circ}$ respectively along with NDVI and brightness criteria.

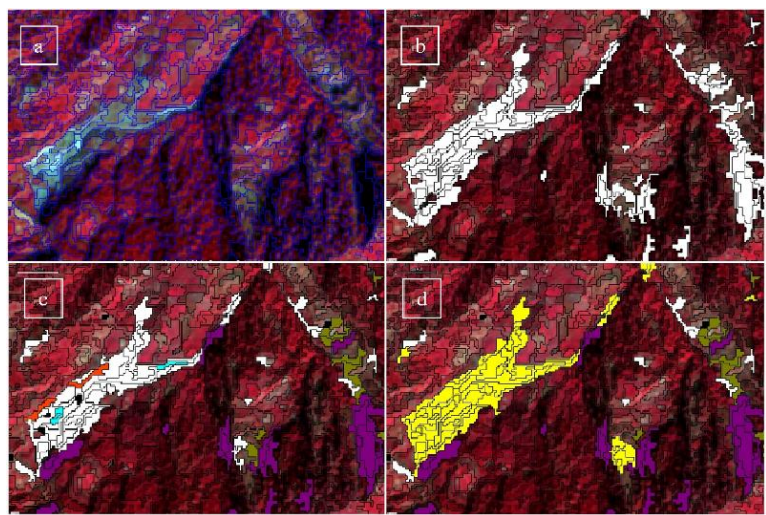

Figure 4. Subset of images representing segmentation process, a) multiresolution segmentation, b) selection of potential landslides (in white), c) removal of false positives, and d) final selection of landslide (in yellow)

After the removal of most false positives, remaining potential landslides with NDVI $<0.3$ and mean slope $>15$ were taken as final landslides. These landslides were merged with surrounding objects when they were sharing $>0.5$ of their border. Also, some random pixels within the landslides were merged. Figure 5 represents selected landslides along with removed false positives Finally, selected landslides were exported as shape-files to be used in accuracy assessment.

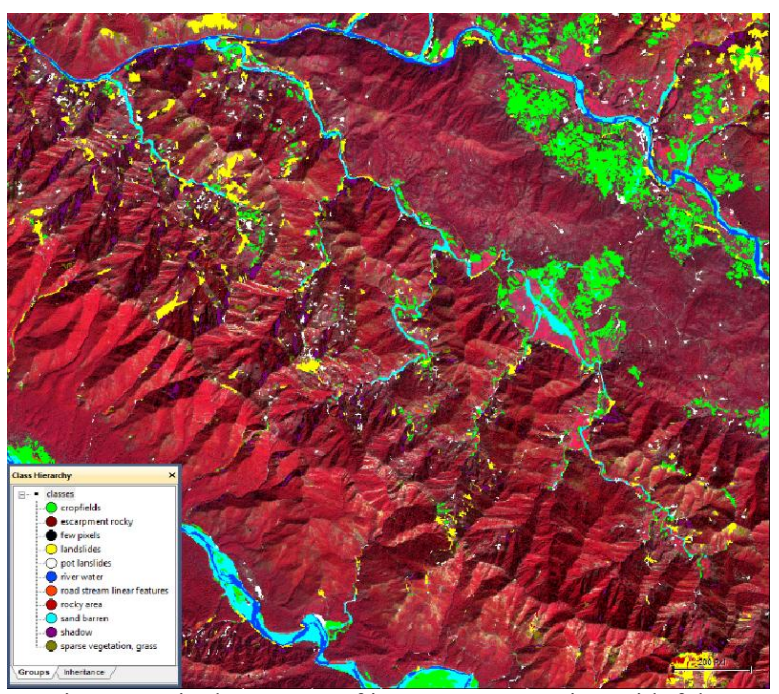

Figure 5. Final outcome of image segmentation with false positives and landslides

\subsection{Accuracy Assessment}

For accuracy assessment landslides the results were compared with the landslide inventory done by Central Department of Environmental Science of Tribhuvan University in the same area in 2016 (PCTMCDB \& CDES-TU, 2017) by manually digitizing over Google Earth and verifying in the field. These landslides were taken as reference landslides. Area-based accuracy measures (i.e. correctness, completeness and quality) (Cai et al., 2018), shape similarity (Lizarazo, 2014), and object matching (Cai et al., 2018) were considered for the accuracy assessment of features extracted by OBIA method.

Area-based accuracy measures are correctness $\left(\mathrm{P}_{\mathrm{AC}}\right)$, completeness ( $\left.\mathrm{P}_{\mathrm{AR}}\right)$ and quality ( $\left.\mathrm{P}_{\mathrm{AL}}\right)$ (Cai et al., 2018) used to evaluate OBIA which are dependent upon the correctly extracted area $\left(A_{C}\right)$, total extracted area $\left(A_{D C}\right)$ of segments and total reference area $\left(A_{R C}\right)$. These are calculated by the following methods:

Correctness $\left(P_{A C}\right)=\frac{A_{C}}{A_{D C}}$

Completeness $\left(P_{A R}\right)=\frac{A_{C}}{A_{R C}}$

Quality $\left(P_{A L}\right)=\frac{A_{C}}{D_{C}}$

All of the above measures results from 0 to 1 where higher values indicate greater matching between extracted objects and reference objects.

Shape Similarity (S) compares geometric structures of extracted objects with that of reference objects and normalized perimeter index (NPI) are used for this purpose. NPI is based on equal area circle (eac), which is a circle with an equal area to that of an object. NPI is calculated as follows:

$N P I=\frac{p_{e a c}}{p_{o b j}}$

where, peac is the eac's perimeter, and pobj is the object's perimeter.

Shape similarity (S) (Lizarazo, 2014) is computed as the ratio of NPI of a classified object to that of a reference object.

$S=r_{n p i^{k}}$

where, $r_{n p i}$ is the ratio of extracted object's NPI to that of reference object's NPI, and

$\mathrm{k}$ is given value +1 if $\mathrm{r}_{\text {npi }}$ is less than or equal to 1 and the value of -1 otherwise.

Object Matching applies maximum overlap area algorithm to estimate coincidence degree $\left(\mathrm{O}_{\mathrm{ij}}\right)$ between evaluated objects and reference objects (Cai et al., 2018) as follow.

$O_{i j}=\frac{1}{2} *\left(\frac{A_{C, i} \cap A_{R, j}}{A_{C, i}}+\frac{A_{C, i} \cap A_{R, j}}{A_{R, j}}\right)$

where, $A_{C, i}$ denotes the area of the $i^{\text {th }}$ evaluated object, $A_{R, j}$ is the area of the $j^{\text {th }}$ reference object, and $A_{C, i} \cap A_{R, j}$ represents the intersection area. 


\section{RESULTS AND DISCUSSION}

The OBIA method deeply scrutinized the Sentinel-2 Image in order to extract landslide features. Among potential landslides from all image objects, 264 were taken as true landslides and rest were false positives.

\subsection{Landslide Inventory}

There were altogether 264 landslides inventoried with a total area measuring be $2484250 \mathrm{~m}^{2}$. The landslide density in all area became $1.8 \mathrm{~km}^{-2}$. The smallest landslide found was of $300 \mathrm{~m}^{2}$ size and largest one scaled $165750 \mathrm{~m}^{2}$. This size range is almost similar to the reference database which is shown in Table 1. Out of total landslides, 95 were found to be located in Lekhgaun and rest 169 were in Bheriganga. Landslide density in Lekhgaun was of $3.39 \mathrm{~km}^{-2}$ and that in Bheriganga was $1.44 \mathrm{~km}^{-2}$. Though landslides number is higher in Bheriganga it can be observed from landslide density that Lekhgaun is highly affected.

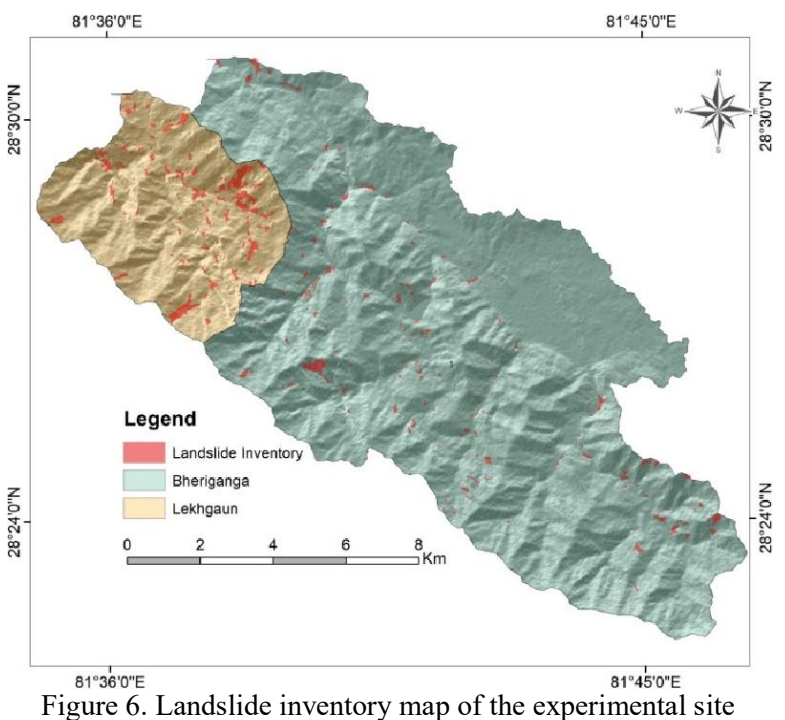

\subsection{Comparisons with reference landslides}

137 out of total OBIA extracted landslides were matching with that of reference landslides (PCTMCDB \& CDES-TU, 2017).

\begin{tabular}{|l|l|l|}
\hline Count & $\begin{array}{l}\text { OBIA } \\
\text { Extracted }\end{array}$ & $\begin{array}{l}\text { Reference } \\
\text { (PCTMCDB \& } \\
\text { CDES-TU, 2017) }\end{array}$ \\
\hline Total Landslides & 264 & 434 \\
Total landslides area & $2484250 \mathrm{~m}^{2}$ & $3009350 \mathrm{~m}^{2}$ \\
Landslide Density & $1.8 \mathrm{~km}^{-2}$ & $2.9 \mathrm{~km}^{-2}$ \\
Minimum size & $300 \mathrm{~m}^{2}$ & $301.32 \mathrm{~m}^{2}$ \\
Maximum size & $165750 \mathrm{~m}^{2}$ & $161465.77 \mathrm{~m}^{2}$ \\
Lekhgaun & $95\left(3.39 \mathrm{~km}^{-2}\right)$ & $106\left(3.78 \mathrm{~km}^{-2}\right)$ \\
Bheriganga & $169\left(1.44 \mathrm{~km}^{-2}\right)$ & $328\left(2.79 \mathrm{~km}^{-2}\right)$ \\
\hline
\end{tabular}

Table 1. Comparisons between OBIA extracted and reference landslides

Though the number and area of landslides extracted by OBIA were lesser than that of reference landslides, almost matching things here was a maximum and minimum size of landslides. Therefore, the ratio of maximum-minimum landslides become 552.50 and 535.87 for OBIA extracted and reference landslides respectively, which signifies the higher object shape matching.

Figure 7 illustrated a scatter plot of OBIA extracted landslides and reference landslides. It is vivid that there less match of landslides along longitude $81.47^{\circ}$ to and $81.76^{\circ}$ which is part of Bheriganga. Higher matching of landslides can be observed in Lekhgaun area along longitudes $81.60^{\circ}$ to $81.64^{\circ}$. In the less matching area of Bheriganga, landslides sized smaller and were covered by dense vegetation, so, thresholds in OBIA were not successful to extract those slides. The probable reason may be shallow slides where grasses, herbs, and shrubs were disturbed but trees remain intact. So, in imagery, the area appears well vegetated and landslides were obscured. In Lekhgaun the size of landslide scars were larger and can be readily mapped. Some landslides in this region that fall under shadow zone were not being able to be extracted by OBIA method.

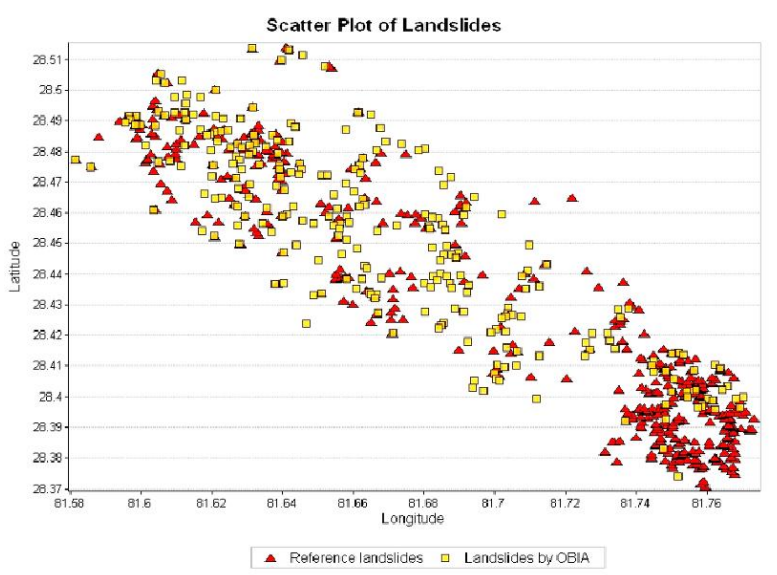

Figure 7. Spatial distribution of OBIA extracted landslides and reference landslides

\subsection{Accuracy Assessments}

Accuracy assessment was done in two stages, first considering all landslides and then using randomly selected matching landslides. 137 landslides were matching out of 264 landslides. Total matching area of landslides was $1994300 \mathrm{~m}^{2}$. These values produce the estimates of area-based accuracy measures which are correctness, completeness and quality. The accuracy results of these three measures were $80.27 \%, 66.27 \%$ and $56.99 \%$ respectively.

\begin{tabular}{|l|l|}
\hline Measure & Accuracy (\%) \\
\hline Correctness & 80.28 \\
Completeness & 66.27 \\
Quality & 56.99 \\
Shape Similarity & 73.03 \\
Object Matching & 62.51 \\
\hline
\end{tabular}

Table 2. Accuracy assessment result of the extracted landslides by different measures

Similarly, 40 matching landslides were selected randomly for shape similarity and object matching assessment. Measurements of matching landslides, in terms of area, shape perimeter, and 
intersecting area, were taken to calculate these accuracy measures. The shape similarity was found to be $73.03 \%$ and object matching was found to be $62.51 \%$.

\section{CONCLUSION}

The feature selection method using the threshold values over different derivatives of image and DEM was successful to extract the landslides in Siwalik Hills of Nepal. Though the findings of this research were within acceptable accuracies it is recommended to work further to obtain higher accuracies. The criteria and thresholds used in ruleset development should be tested to other parts of Siwalik Hills or at the regional level for the acceptability of the method applied. The freely available image of Sentinel-2 and ASF-RTC-DEM proved useful for this purpose of landslide feature extraction.

\section{ACKNOWLEDGEMENTS}

We would like to acknowledge Centre for Space Science and Technology Education in Asia and the Pacific, Dehradun, India for their financial as well as material support to conduct this research successfully.

\section{REFERENCES}

Aksoy, S., Akcay, H. G., 2005. Multi-resolution segmentation and shape analysis for remote sensing image classification. Proceedings of 2nd International Conference on Recent Advances in Space Technologies, 599-604. https://doi.org/10.1109/RAST.2005.1512638.

Alexander, D., 2004. Vulnerability to Landslides. In T. Glade, M Anderson, M. J. Crozier (Eds.), Landslide Hazard and Risk. 175198. https://doi.org/10.1002/9780470012659.ch5.

Baatz, M., Schäpe, A., 2000: Multiresolution segmentation: an optimization approach for high quality multi-scale image segmentation. In J. Strobl, T. Blaschke, G. Griesbner (Eds.), Angewandte Geographische Informations-Verarbeitung XII. 1223.

http://www.ecognition.com/sites/default/files/405_baatz_fp_12. pdf.

Bhatt, B. P., Awasthi, K. D., Heyojoo, B. P., Silwal, T., Kafle, G., 2013. Using Geographic Information System and Analytical Hierarchy Process in Landslide Hazard Zonation. Applied Ecology and Environmental Sciences, 1(2), 14-22. https://doi.org/10.12691/aees-1-2-1.

Böck, S., Immitzer, M., \& Atzberger, C., 2017. On the Objectivity of the Objective Function - Problems with Unsupervised Segmentation Evaluation Based on Global Score and a Possible Remedy. Remote Sensing, 9(8), 769-778. https://doi.org/10.3390/rs9080769.

Budha, P. B., Paudyal, K., \& Ghimire, M., 2016. Landslide Susceptibility Mapping in Eastern Hills of Rara Lake, Western Nepal. Journal of Nepal Geological Society, 50, 125-131. https://doi.org/10.3126/jngs.v50i1.22872.

Cai, G., Ren, H., Yang, L., Zhang, N., Du, M., Wu, C., 2019 Detailed Urban Land Use Land Cover Classification at the Metropolitan Scale Using a Three-Layer Classification Scheme. Sensors, 19(14), 3120. https://doi.org/10.3390/s19143120.
Cai, L., Shi, W., Miao, Z., \& Hao, M., 2018. Accuracy Assessment Measures for Object Extraction from Remote Sensing Images. Remote Sensing, 10(2), 303-316. https://doi.org/10.3390/rs10020303.

Chen, Z., Zhang, Y., Ouyang, C., Zhang, F., Ma, J., 2018 Automated Landslides Detection for Mountain Cities Using Multi-Temporal Remote Sensing Imagery. Sensors, 18(3), 821. https://doi.org/10.3390/s18030821.

Cheng, G., \& Han, J., 2016. A survey on object detection in optical remote sensing images. ISPRS Journal of Photogrammetry and Remote Sensing, 117, 11-28. https://doi.org/10.1016/j.isprsjprs.2016.03.014.

Dahal, R. K., Yamanaka, M., Hasegawa, S., Bhandary, N. P., Yatabe, R., 2010. Statistical and deterministic landslide hazard assessment in the Himalayas of Nepal. In Williams, A.L., Pinches, G.M., Chin, C.Y., McMorran, T.J., Massey, C.I. (Eds). Geologically Active. Proceedings of the 11th IAEG Congress. Auckland, New Zealand. 1053-1060

Dhital, M. R., 2015. Physiography of Nepal. In Geology of the Nepal Himalaya: Regional Perspective of the Classic Collided Orogen. pp. 23-33. https://doi.org/10.1007/978-3-319-0249673

Espindola, G. M., Camara, G., Reis, I. A., Bins, L. S., Monteiro, A. M., 2006. Parameter selection for region - growing image segmentation algorithms using spatial autocorrelation. International Journal of Remote Sensing, 27(14), 3035-3040. https://doi.org/10.1080/01431160600617194.

Ghimire, M., 2010. Landslide occurrence and its relation with terrain factors in the Siwalik Hills, Nepal: case study of susceptibility assessment in three basins. Natural Hazards, 56(1), 299-320. https://doi.org/10.1007/s11069-010-9569-7.

Gustafson, K. B., Coates, P. S., Roth, C. L., Chenaille, M. P., Ricca, M. A., Sanchez-Chopitea, E., Casazza, M. L., 2018. Using object-based image analysis to conduct high- resolution conifer extraction at regional spatial scales. International Journal of Applied Earth Observation and Geoinformation, 73(June), 148155. https://doi.org/10.1016/j.jag.2018.06.002.

Hay, G. J., Castilla, G., 2006. Object-Based Image Analysis: Strengths, Weaknesses, Opportunities and Threats (SWOT). Int Arch. of the Photogramm. Remote Sens. Spatial Inf. Sci., XXXVI (4/C42), 8-10.

Karki, R., Talchabhadel, R., Aalto, J., Baidya, S. K., 2016. New climatic classification of Nepal. Theoretical and Applied Climatology, 125(3-4) 799-808. https://doi.org/10.1007/s00704-015-1549-0.

Karna, B. K., Bhardwaj, A., 2014. Integrated approach for building extraction from InSAR and optical image using object oriented analysis technique. Nepalese Journal on Geoinformatics, 13, 16-23. Retrieved from https://www.nepjol.info/index.php/NJG/article/view/16933.

Kayastha, P., Dhital, M. R., De Smedt, F., 2013. Evaluation and Comparison of GIS based Landslide Susceptibility Mapping Procedures in Kulekhani Watershed, Nepal. Journal of the Geological Society of India, 81(2), 219-231. https://doi.org/10.1007/s12594-013-0025-7. 
Lizarazo, I., 2014. Accuracy assessment of object-based image classification: another STEP. International Journal of Remote Sensing $35(16)$,

6135-6156.

https://doi.org/10.1080/01431161.2014.943328.

Martha, T. R., Kerle, N., van Westen, C. J., Jetten, V., Kumar, K V., 2011. Segment Optimization and Data-Driven Thresholding for Knowledge-Based Landslide Detection by Object-Based Image Analysis. IEEE Transactions on Geoscience and Remote Sensing, 49(12), 4928-4943. https://doi.org/10.1109/TGRS.2011.2151866.

PCTMCDB, CDES-TU, 2017. Characterization of Landslide Hazard and Design of Mitigation Works of High Risk Landslides in Chure Area of Nepal. President Chure Tarai Madhesh Conservation Development Board, Central Department of Environmental Science-Tribhuvan University, Kirtipur, Kathmandu.

Schelling, D., Cater, J., Seago, R., Ojha, T. P., 1991. A Balanced Cross-Section across the Central Nepal Siwalik Hills; Hitauda to Amlekhganj. Journal of the Faculty of Science, 23(1), 1-9. 